\title{
Adoção de inovação em serviços de saúde: a implementação do PACS no Instituto Nacional do Câncer (INCA)
}

\author{
Antônio Augusto Gonçalves \\ Doutor em Engenharia de Produção - Universidade Federal do Rio de Janeiro (UFRJ). \\ augusto@inca.gov.br \\ José Geraldo Pereira Barbosa \\ Doutor em Administração - Universidade Federal do Rio de Janeiro (UFRJ). \\ jose.geraldo@estacio.br \\ Carlos Henrique Fernandes Martins \\ Mestre em Saúde Pública - Escola Nacional de Saúde Pública - ENSP-FIOCRUZ. \\ cmartins@inca.gov.br
}

\begin{abstract}
RESUMO: O objetivo desta pesquisa foi investigar os fatores que determinaram a adoção rápida do Picture Archiving Communication System (PACS) no Instituto Nacional de Câncer (INCA). A pesquisa foi conduzida por meio de um estudo de caso único. Entre os benefícios mais importantes da implementação do sistema, foram identificados: diagnósticos mais rápidos; redução significativa no número de imagens perdidas; elevado número de pacientes examinados; redução do número de imagens rejeitadas (e exames remarcados); mais produtividade de radiologistas e tecnólogos; eliminação de filmes e produtos químicos necessários para revelá-los e melhor atendimento ao paciente. Os resultados sugerem que a velocidade da adoção do PACS foi influenciada pela forma como o hospital gerenciou sua implementação, em especial os seguintes aspectos: colaboração entre parceiros; comunicação entre participantes; resistência à mudança; suporte de Tl; treinamento do pessoal envolvido; e abordagem sistêmica, ou seja, consideração de todos os fatores de natureza técnica, econômica, organizacional e humana que afetavam o projeto.
\end{abstract}

PALAVRAS-CHAVE: Serviços de saúde; Inovação em processo; Sistema de informação.

\section{Innovation adoption in healthcare practice: the implementation of pacs at the Brazilian National Cancer Institute (INCA)}

ABSTRACT: The purpose of this research was to investigate the factors that determined the rapid adoption of the Picture Archiving and Communication System (PACS) at the Brazilian National Cancer Institute (Instituto Nacional de Cancer - INCA). This research was developed through a holistic single-case study. Among the more important benefits, we can point to rapider diagnostic readings, a significant reduction in the number of lost images, a greater number of patients examined, fewer rejected images (and rescheduled exams), accelerated improvements in the productivity of radiologists and technologists, the elimination of film and the chemical products needed to develop it, and improved patient care. The survey results suggest that the speed of adoption of PACS was influenced by how the hospital managed its implementation, in particular the following aspects: collaboration between partners, team communication, resistance to change, IT support, staff training, and systemic approach, i.e., consideration of all technical, economic, organizational and human factors that affected the project.

KEY WORDS: Health care; Process innovation; Information system.

\footnotetext{
1 Submetido em 28 de Agosto de 2012. Aceito em 20 de Dezembro de 2012. O artigo foi avaliado segundo o processo de duplo anonimato além de ser avaliado pelo editor. Editores responsáveis: Márcio Augusto Gonçalves e Lucas Maia dos Santos.
} Reprodução parcial ou total de trabalhos derivativos permitidos com a citação apropriada da fonte. 


\section{INTRODUCTION}

Some new practices enjoy rapid diffusion throughout health systems, even when they are of limited benefit or unproven efficacy, or represent risks to patients, while other innovations that could secure better outcomes for patients never make it to the bedside (Dixon, 2011).

The purpose of this research was to investigate the factors that determined the rapid adoption of the Picture Archiving and Communication System (PACS) at the Brazilian National Cancer Institute (Instituto Nacional de Cancer - INCA). The Picture Archiving and Communication System (PACS) is composed of computing systems and components that are used for capturing, transferring, storing and displaying digital information. DICOM (Digital Imaging and Communication in Medicine), a standard format for digital medical data, was established for communication among PACS components (Baumann, 2000).

\section{INNOVATION IN HEALTHCARE SERVICES}

Governments around the world have focused on innovations, sustainability and priority- setting within their healthcare systems. Innovation has become a central issue. The motivations for these initiatives range from difficulties in using and sharing available scientific knowledge, to rapidly rising costs due to changing demographics and medical technology (Hartman, Martin, McDonnell, \& Catlin, 2009).

Besides the controversial nature of innovation, public healthcare services represent an additional challenge due the fact that they affect multiple stakeholders (Hartley, 2005). Although some studies indicate that motivation to innovate in public services is missing and employees have few alternatives, the reality is that there is a growing pressure for change coming from multiple and often conflicting directions. Demands for cost reduction influence providers to look for more-efficient solutions.

\subsection{Innovation Typology}

Tidd and Bessant (2009) have classified innovation according to four dimensions or types of changes:

- Product innovation: that is, innovation characterized by a change in what is offered (goods or services);

- Process innovation: innovation characterized by a change in how products or services are created, provided or offered;

- Position innovation: innovation represented by a change in the context in which products or services are introduced;

- Paradigm innovation: innovation characterized by a basic change in mental models that guide what the company does.

According to Johannessen, Olsen and Lumpkin (2001), innovations can be oriented in four directions:

- Individual-oriented innovation: emphasizes the role of individual characteristics such as age, educational level, gender, cognitive style and creativity.

- Structure-oriented innovation: stresses how organizational structures either catalyze or inhibit innovation;

- Iterative-oriented innovation: emphasizes how actions affect structures and processes, considering the political organization.

- System-oriented innovation: stresses the role of national and regional innovation systems as they influence the activity of innovation in enterprises.

Damanpour, Walker and Avellaneda (2009, p.654) characterize innovation in services as "... an introduction of new services in place of existing services or introduction of new services to new customers, or introduction of new services to present customers." Innovation in healthcare may assume many types, which typically range from product, process, to structure. Innovation can vary from new drug therapies and surgical procedures, to innovative forms of professional health training, patient education, management, financing and service delivery models. (Varkey et al., 2008) IBGE, the Brazilian governmental institution which conducts the research PINTEC (Pesquisa de Inovação Tecnológica - Technological Innovation Research), defines:

... process innovation as the introduction of new or significantly improved production technology, methods of offering services or handling and delivery of new or significantly improved products, as well as new or significantly improved equipment and software in production support activities. The result of the adoption of new or substantially improved process must be significant in terms of increased product quality (good/ service) or decrease in unit cost of production and delivery. The introduction of this process can be aimed at the production or delivery of new or significantly improved 
products, which cannot use the previously existing processes, or simply increase the efficiency of production and delivery of existing products. (IBGE, 2008)

...organizational innovation includes the implementation of new management techniques or significant changes in work organization and company external relations, aimed at improving the use of knowledge, the efficiency of workflow or quality of goods or services. It must be the result of strategic decisions taken by management and should be seen as newness for the company. (IBGE, 2008)

Organizational innovations usually affect the internal and external infrastructure and create new business models. By their very nature, organizational changes are more likely to be disruptive because they represent major changes in the way services are delivered, as is the case with group practice. According to Tigre (2006), changes in organizational processes are more difficult to implement than changes in technology because they require alterations in business processes, changes in command and control of hierarchical chains, new ways to access data, and changes in long-lived organizational routines. We may consider the implementation of PACS as a kind of innovation located the frontier between process and organizational innovation. On the other hand, Minute Clinics, with their limited diagnostic and treatment service, are an example of a non-disruptive organizational innovation. These clinics are easily accessible, efficient, and cost-effective. Table 1 presents some examples of innovations.

Table 1. Examples of Innovations in Healthcare.

\begin{tabular}{lll}
\multicolumn{1}{c}{ Type of Innovation } & \multicolumn{1}{c}{ Non-Disruptive } & \multicolumn{1}{c}{ Disruptive } \\
\hline Product & Newer generation drugs & MRI, CT scan \\
\hline Process & Telemedicine & PACS, Digital Imaging \\
\hline Organizational & Minute Clinics & Group Practice
\end{tabular}

Source: Adapted from Varkey et al. (2008).

Abbreviations: MRI = Magnetic Resonance Imaging; CT = Computerized Tomography.

Regarding risks, Brown (2005, p. 60) states that “...they are one of the essential conditions for innovation to occur." He suggests that the greater the risk present in the innovation, the greater the innovation's potential to generate better results. Baptista (1997) highlights a number of complex and crucial decisions that companies face under conditions of uncertainty and risk: i) decisions on investing in expansion of capacity, ii) decisions on entering or leaving markets; iii) decisions on choosing between diversification and specialization of activities, iv) decisions regarding the choice to enter a particular technological trajectory (and even the time of this decision), particularly in situations of uncertainty among competing paths, and $v$ ) decisions related to investment made in research and development ( $R$ \& D) and, in particular, in the adoption of technological strategies.

Despite the inherent risks, innovation has been identified as an important task of public sector agencies. Innovation has the role of improving performance, enabling organizations to meet the changing needs of clients, lowering costs, and increasing efficiency (Mulgan \& Albury, 2003).

\title{
2.2. Innovation in Organizational Processes: Technology, Impacts
}

On organizational processes, Gonçalves (2000) states that:

\begin{abstract}
There are three basic categories of processes: essential or business process (client centered) are those directly linked to the company's performance and supported by other internal processes, resulting in the product or service that is received by an external customer; organizational processes are centered in the organization and enable the coordinated operation of various subsystems of the organization for its overall performance, ensuring adequate support to business processes; and management processes are focused on managers and their relationships (Garvin, 1998) and incorporate the actions for measuring e adjusting of the organization performance.
\end{abstract}

The customer does not usually pay directly for the process, but the process is required to deliver a product or service. A process innovation, therefore, may be a change in the manner of producing or 
delivering the product, which allows for a significant increase in the value delivered to customers, as well as a reduction in costs. The value chain developed by Porter (2005) is an important link between the organization's strategies and activities, or rather, its processes. And it is through the value chain that one has a first idea of the macro-processes of the organization. The value chain as a strategic tool concentrates on analyzing the various organizational processes responsible for generating some kind of customer value. This is because, by knowing how activities are implemented and how the links between them occur, it is possible to seek market differentiation through a cheaper process and to deliver a product / service of good quality. In short, the value chain approach divides the organization into macroprocesses, which in turn can be subdivided into processes and activities. Through this division, one can list the processes that are critical to the organization, define criteria for prioritizing investments, i.e., what process should be changed or improved, and develop performance indicators based on processes. (Araújo, Garcia \& Martines, 2011)

Regarding innovation in internal processes, Tidd and Bessant (2009) suggest that structural elements be evaluated for possible obsolescence of equipment and systems as a result of the innovation and for whether the physical layout and facilities are prepared to receive it; that infrastructure elements be evaluated to verify whether the operational control systems and management are prepared for the innovation; and lastly, that changes in work routines that may generate the need for new skills in operation and maintenance be taken into consideration.

The technology used in process automation can be categorized into four types: solid technology, which was formerly done by people but is now done by equipment; hybrid technology, which was formerly done by people and still is, but with the help of specially designed equipment; and lightweight technology, which was formerly done by people and still is through special routines based on the division of labor according to some kind of expertise. (Gianesi \& Correa, 1994) According to Tidd and Bessant (2009) the technologies incorporated into equipment/ systems can be classified according to the stage of their life cycle as to:

- Basic technologies - those that are based on innovations in products and processes that are vital to the business. However, they are also widely known and used by competitors and thus provide little competitive advantage.

- Key technologies - those that constitute the core of the current processes and products of the organization and offer a high competitive impact. They are strategically important to the organization and can be well protected by patents or other means.

- Pacing technologies - those that are leading the present competitive game and can also be experienced by competitors. They have a high but still unproven competitive potential.

- Emerging technologies - those that are on the technological frontier, still under development and whose impact is promising but not yet very clear.

Gianesi and Correa (1994) state that four issues must be considered when investing in equipment/ systems: collaboration for the performance objectives of the organization; economic (return) and operational (ability to use them) viability; life cycle maintenance costs; and the risks of adoption and non-adoption of the technology incorporated.

If a new technology or technique is being considered for use, health systems should consider the principles of quality improvement when they are introduced rather than wait for the inevitable problems to occur. (Dixon, 2011)

Innovation is driven by information technology (IT). Most of the changes in medical practices revolve around IT. Studies on innovation have shown that the success and survival of the healthcare industry depends on the effectiveness and efficiency of IT implementation. (Liaw, 2002). Advances in information technology will help healthcare managers establish the basis for fundamental changes within the healthcare organization. Besides enabling physicians to communicate easily and quickly with patients and staff members, it will also increase community awareness about healthcare through online healthcare forums and other health information systems. (Lester, 2007)

When it comes to health services, information about patients must be protected so that unauthorized access, unauthorized changes and outages are avoided. According to Sêmola (2003), information security should be guided by three principles:

- Confidentiality - all information should be protected according to the degree of secrecy of its content, aimed at limiting its access and use only to people for whom it is intended; 
- Integrity - all information should be kept in the same condition it was in when released by its owner in order to protect it from unauthorized changes, whether intentional or accidental;

- Availability - all information generated or acquired by an individual or institution should be available to users whenever they need it for any purpose.

By thinking carefully and critically about when we should introduce a new technology or technique and when we should consider reorganization as a normal part of the continuous experiential learning required to improve healthcare, we remain alert to the possible negative and positive impacts of innovation. Such impacts may involve the disposing of old knowledge and training and the developing of new abilities, in addition to the discarding of technologies made incompatible by the changes, and so on. These are all difficult challenges and require courage in the face of uncertainty, political queries, patient and provider pressures, as well as organizational and institutional inertia. Perhaps most importantly, these challenges require the courage to adopt learning by trial and error and to face the possibility of failure. (Daniels, 2006)

According to Fichman (2000), the organization's intention to adopt a technology is influenced by a number of other factors, including the cost of the desired innovation, its user-friendliness, the technology's compatibility with existing systems, and its alignment with the organizational structure. Some innovations like PACS require a level of investment, training or reinforcement that healthcare organizations have difficulty achieving.

Improvement in healthcare clearly depends on change, but change always creates new challenges. Quality improvement systems may struggle to keep the effects of new practices or technologies under control. Generally speaking, the lack of adequate performance indicators at the start of innovations make managers feel uncomfortable. (Varkey et al., 2008) Regarding the impact of innovations, the Technological Innovation Research, conducted by IBGE and known by the name PINTEC, presents several indicators to assess the impact of innovations on industries and services in Brazil. (IBGE, 2008) These indicators are grouped into four categories:

- Product: improvement in product quality; increase in the range of products offered.

- Market: maintaining of the company's share in the market ; increase in market share; opening of new markets.

- Process: increase in production capacity; increase in production flexibility; reduction in production costs; reduction in labor costs; reduction in consumption of raw materials; reduction in energy consumption; reduction in water consumption.

- Other impacts: reduction in environmental impact; increased control of aspects related to health and safety; increased compliance with regulations and standards.

\subsection{Diffusion of Innovations}

Diffusion is the process by which an innovation is communicated over time and through certain channels to members of a social system. It is a special type of communication, in which the messages refer to new ideas. Diffusion has to be considered on two dimensions: the adoption rate and the direction of the adoption (who is adopting the innovation?). The process of diffusion usually faces four different types of barriers: economic - personal costs versus benefits, access to information, insufficient incentives; behavioral priorities, motivations, rationality, inertia, propensity to change and risk aversion; organizational - goals, practices, power and influence, culture and stakeholders; and structural - infrastructure "sunk" costs, governance. (Tidd \& Bessant, 2009)

The above-mentioned authors state that some characteristics of innovations affect their rate of adoption:

- Relative advantage: the degree to which an innovation is perceived as better than the product/service it replaces or competes with. Financial and non-financial factors dictate such an advantage.

- Compatibility: the degree to which an innovation is perceived as being consistent with the values, experience and present needs of potential adopters. There are two distinct aspects of compatibility skills and practices, and values and norms.

- Complexity: the degree to which an innovation is perceived as being difficult to understand or use.

- Ability to be experienced: the degree to which an innovation can be experienced presents less uncertainty for potential adopters and enables "learning by doing."

- Visibility: the extent to which the results of an innovation are visible to others.

Tigre (2006) states that the adoption of innovations may lead to certain types of adopter imprisonment (switching costs). Table 2 illustrates some cases: 
Table 2. Switching costs.

\begin{tabular}{ll} 
If the adoption requires... & Costs of abandoning the innovation are... \\
\hline Contractual commitments & Financial compensation for breach of contract \\
\hline Use licensing & Need of acquiring new licenses \\
\hline Buying of equipment/systems & Replacement of equipment, peripherals and accessories \\
\hline Training & Learning of a new system \\
\hline Information and databases & Conversion of programs and data \\
\hline Specialized suppliers & Development of new suppliers \\
\hline Search costs & Experimentation costs \\
\hline Loyalty programs & Benefits lost by the user
\end{tabular}

Source: Adapted from Tigre (2006).

\subsection{Implementation of Innovations: Internal and External Collaboration}

The implementation of innovations without proven efficacy introduces several threats to quality and cost control. Once institutions have invested in a new technology like PACS, they have a huge interest in recovering costs.

An organization will be interested in adopting an innovative idea if such idea gives it a competitive advantage. At the same time, complexity and compatibility of the new technology influence the adoption decision. Walker (2006) shows that, although electronic medical records (EMRs) have been around since the 1960s, until recently they were not adopted extensively because of the complexity of maintaining patients' electronic medical records.

According to Tidd and Bessant (2009), the use of partnerships for implementing innovations is justified when the technology is not vital (from the competitive point of view); when there is time pressure; when a partnership would reduce uncertainty; and when the organization lacks managerial and technical capacity for innovation development. Such partnerships can occur in various ways: joint payment for the development of innovation; technology licensing; strategic alliances for development; joint ventures; cooperation networks; hiring of foreign specialists; partnerships with clients and suppliers, and so on. According to the authors, the main factors that facilitate knowledge transfer between partners involved in the implementation of innovations are: identification of "project champions" who believe in the importance of the technology being transferred; ease of communication between participants in the transfer process (informality); face-to-face transfer methods; facilitating of the movement of workers between the organizations involved; and end-user participation.

Regarding the use of suppliers as a source of technology, Ragatz, Handfield and Scannell (1997) note that buyer and supplier must overcome obstacles such as resistance to sharing information and the "not invented here" syndrome. In a study of sixty member companies of the Michigan State University Global Procurement and Supply Chain Electronic Benchmarking Network, these authors analyzed some management practices that contribute to the relationship with suppliers for the successful development of new products or processes, namely: (i) the commitment of senior management of both companies, (ii) shared education and training, (iii) supplier reputation, (iv) agreement on common performance measures, ( $v$ ) agreement on sharing risks and rewards, (vi) sharing of information about customers requirements, (vii) reliance on formal processes of development, (viii) information systems connected, (ix) sharing of information, technology, facilities and equipment, ( $x$ ) participation in the supplier's staff project, (xi) co-location of customer and supplier employees, and (xii) cross-functional communication.

According to the above-mentioned authors, good practices in implementing innovations include: 1) recognizing that any implementation of successful innovation is never completely reproducible, i.e., it is necessary to compare the organizational context in which the implementation occurred with the context of one's own organization, economic sector, technology and country; 2) properly structuring the teams responsible for implementation by choosing representatives from all departments involved in innovation and giving them the autonomy to develop the project; 3 ) linking the project team in the most appropriate manner to the rest of the organization; 4) promoting early involvement of all relevant sectors; 5) promoting a shared vision of the project, making sure that everyone is working toward the same goals, and encouraging communication, information exchange and dialogue; 6 ) and lastly, allowing 
space for improvisations and acceptance of changes in light of new (and often unexpected) evidence.

Professional boundaries, particularly between different disciplines and occupational groups, may create barriers to proper collaboration. Social movements can become sites of struggle and contestation, and may never succeed in fully achieving their aims (Pope, 2003)

One of the most effective ways of ensuring the implementation of new technologies, therapies and techniques is by working cooperatively with the professional groups that are expected to engage in implementing it; however, relying solely on cooperation may also be the most effective way of killing an innovation. (Dixon, 2011)

Collaboration is one of the major drivers of innovation in healthcare. Open communication, interpersonal relations and networks, and close connections between innovators are frequently stated to be necessary criteria for an innovative organization. This practice should be encouraged across functional and organizational boundaries.

A recent study in a cancer care hospital showed that healthcare organizations that emphasize constructive relationships among workers, including participating in social activities in which best practices are shared with other team members, were found to be successful in dealing with innovations. The study also indicated that those healthcare organizations that are hierarchical in nature have professional conflicts and are less creative. (Ekedahl, 2008)

People resist change. Change often temporarily disrupts routines in patient care. Depending on the complexity level, implementing innovations can be troublesome. The difficulties may come from misunderstanding the needs of the related services, techniques and technology. Therefore, to deal with these problems a systematic approach must be used.

Organizational culture usually encourages the perpetuation of the existing strategy rather than changes in strategy; at best it tends to promote changes in position within the organization's strategic perspective. Therefore, radical changes in strategy must also rely on fundamental changes in culture. (Mintzberg et al., 2005) The authors propose a number of ways to overcome cultural barriers to strategic changes: 1) introducing the value of innovation and flexibility into the organizational culture; 2) making organizational beliefs visible; in other words, if managers are aware of their shared beliefs, there is less chance of remaining blind to them; 3 ) promoting flexibility (top manager without portfolio; in-company courses with external instructors; rotation of managers within offices and business areas; hiring of managers from another organization; encouraging of middle managers to issue their opinions; participation of managers in MBA courses).

On the other hand, Hernandez and Caldas (2001) suggest a new approach to breaking through resistance. In light of the fact that this subject has been vastly researched, they ask why resistance is still a major barrier to organizational transformation, and why so many change agents still strive to overcome it. In their article they:

\footnotetext{
"...attempt to respond this question by questioning the predominant models of resistance and the assumptions of the several "recipe-oriented" approaches to deal with resistance in organizations. Our understanding is that such "recipes" are not particularly helpful because they use a model of resistance to change that was built upon several questionable assumptions, according to which resistance is a) a "natural", inevitable fact; b) malignant to the organization; c) employee driven; and d) collective. Based on counter-assumptions to each of these wide spread premises and on Psychology of Perception, a new Model of Individual Resistance to Change is proposed. (Hernandez \& Caldas, 2001, p. 31)
}

Table 3 shows the classical assumptions about resistance to change and the possible counter-assumptions proposed by Hernandez and Caldas (2001).

The implementation must start in the department or functional area where the innovation was initially required. From that initiative, the results and/or performance are evaluated, modifications are made, and then the new service/technology is gradually rolled out to other departments and/or functional areas when deemed appropriate. Innovation means selling a concept; thus, communication and feedback are keys to its success. (Thakur et al., 2011) 
Table 3. Classical assumptions about resistance to change and possible counter-assumptions.

\begin{tabular}{|c|c|}
\hline Classical assumption & Counter-assumption \\
\hline $\begin{array}{l}\text { - Resistance to change is a "fact of life" and } \\
\text { should happen during any organizational inter- } \\
\text { vention. }\end{array}$ & $\begin{array}{l}\text { - Resistance is rare; it only happens in exceptional circumstances. } \\
\text { - In trying to prevent resistance, agents of change end up actu- } \\
\text { ally contributing to it or even worsening it. } \\
\text { - Resistance is a behavior heralded by power holders and agents } \\
\text { of change when their privileges or actions are challenged. }\end{array}$ \\
\hline $\begin{array}{l}\text { - Resistance to change is harmful to the efforts } \\
\text { of organizational change. }\end{array}$ & $\begin{array}{l}\text { - Resistance is a healthy and contributory phenomenon. } \\
\text { - Resistance is used as an excuse for failed or inadequately de- } \\
\text { signed change processes. }\end{array}$ \\
\hline - People are naturally resistant to change. & $\begin{array}{l}\text { - People are resistant to loss, but they do want change: this need } \\
\text { typically overlaps a fear of the unknown. }\end{array}$ \\
\hline $\begin{array}{l}\text { - Employees are organizational actors who are } \\
\text { more likely to resist change. }\end{array}$ & $\begin{array}{l}\text { - Resistance - when it occurs - can happen among managers, } \\
\text { change agents and employees. }\end{array}$ \\
\hline $\begin{array}{l}\text { - Resistance to change is a group/collective } \\
\text { phenomenon. }\end{array}$ & $\begin{array}{l}\text { - Resistance is both individual and collective - resistance will } \\
\text { vary from one person to another due to several situational and } \\
\text { perceptual factors. }\end{array}$ \\
\hline
\end{tabular}

Source: adapted from Hernandez \& Caldas (2001)

The implementation of innovations in healthcare organizations is supported by training courses or other kinds of education. Expenditures incurred for training and education are considerable. In the USA an average healthcare organization's annual training expenditures exceed $\$ 150,000$. (Varkey et al., 2008)

Meyers and Sivakumar (1999) recognized training and education as key factors to inducing organizational innovation. Training can create a positive climate and attitude by expanding understanding and technical competence. Training not only leads to more specialization, which in turn can lead to a broader knowledge base, but it plays an important role in the exchange of ideas and the diffusion of innovations.

\section{METHODOLOGY}

This study was carried out using qualitative research designed to present a descriptive analysis of PACS' implementation within the National Cancer Institute (Instituto Nacional de Cancer [INCA]). A holistic single-case study - the kind of research employed in this study - intends to contribute to the knowledge of organizational phenomena, presenting a contemporary description of the system implemented, using an empirical inquiry to answer the questions what, who, where and how (Cooper and Schindler, 2003; Yin, 2003). The implementation of PACS at INCA was chosen as a unit of analysis in order to take advantage of the professional experience of two of the authors while working in its Information Technology Division.

The investigation was to be exploratory in nature and it was believed that, through direct observation and semi-structured interviewing, the case study methodology would be the most valuable to demonstrate process innovation. While case study research has been frequently criticized for its lack of rigor, we closely followed suggestions from previous researchers to ensure the validity of the study. Therefore, following Yin's suggestions (1994), several validity tests (construct validity, external validity, and reliability) were conducted to ensure the quality of the research.

The first author is INCA's Chief Information Officer [CIO] and is an associate professor in the Business Administration graduate program that has been conducting this study. The second author is a full professor in the same program, and the third is the infrastructure manager of INCA's Information Technology Division.

\section{PACS' IMPLEMENTATION AT INCA}

Brazil currently has a complex cancer scenario. General incidence and mortality rates are elevated, with a particularly high incidence of prostate cancer in men and breast cancer in women. These cases have been responsible for over one hundred thousand deaths per year. There are approximately 480,000 new diagnoses of cancer each year in Brazil, and the vast majority of these patients have had some contact with hospital services. However, research also shows that, in several regions of the country, long waiting lists for diagnostics and treatments have become commonplace, which has led to a situation of 
people being diagnosed with cancer at a very advanced stage (National Cancer Institute [INCA], 2008). These sad findings have motivated the national health care ministry in recent years to initiate a series of challenging reforms in order to implement early clinical diagnostic procedures. The management of cancer treatment is a long and complex process, and the reduction of the patient's waiting time to start cancer treatment plays an increasingly important role. Therefore, any environment focusing on accessibility to the treatment of a chronic illness like cancer should make every effort to avoid medical errors and fragmentation of care delivery.

INCA is an agency under the direct administration of the Ministry of Health, associated with the health care secretariat. INCA has five specialized hospital units and is a large organization with over 650 physicians plus a combined health staff of nearly 3,400. It treats over 50,000 outpatients per year and has approximately 350 inpatient beds with over 13,000 hospital admissions per year.

PACS consists of technical and clinical components related to medical imaging to form an integrated healthcare information technology system. Due to its medical imagery, storage, information communication technologies, display, and clinical workflow, it has revolutionized the practice of radiology, and in a sense, of medicine. (Huang, 2011). Its implementation at INCA was made with the support of the company Carestream Health (formerly Kodak), which provided the entire solution (hardware and software). The project required the integration of the solution with different equipment/systems (tomography, X-ray, mammography, magnetic resonance, etc.) from different manufacturers.

It can be considered an essential hospital sub-process, as shown in Figure 1. It is centered on patients, supported by other internal processes, and adds value to the services provided to patients. The value added to the service has been felt by patients in terms of speediness of attendance and higher quality of diagnostics. For cancer treatment, such points are relevant factors for success.

Figure 1. PACS main tasks.

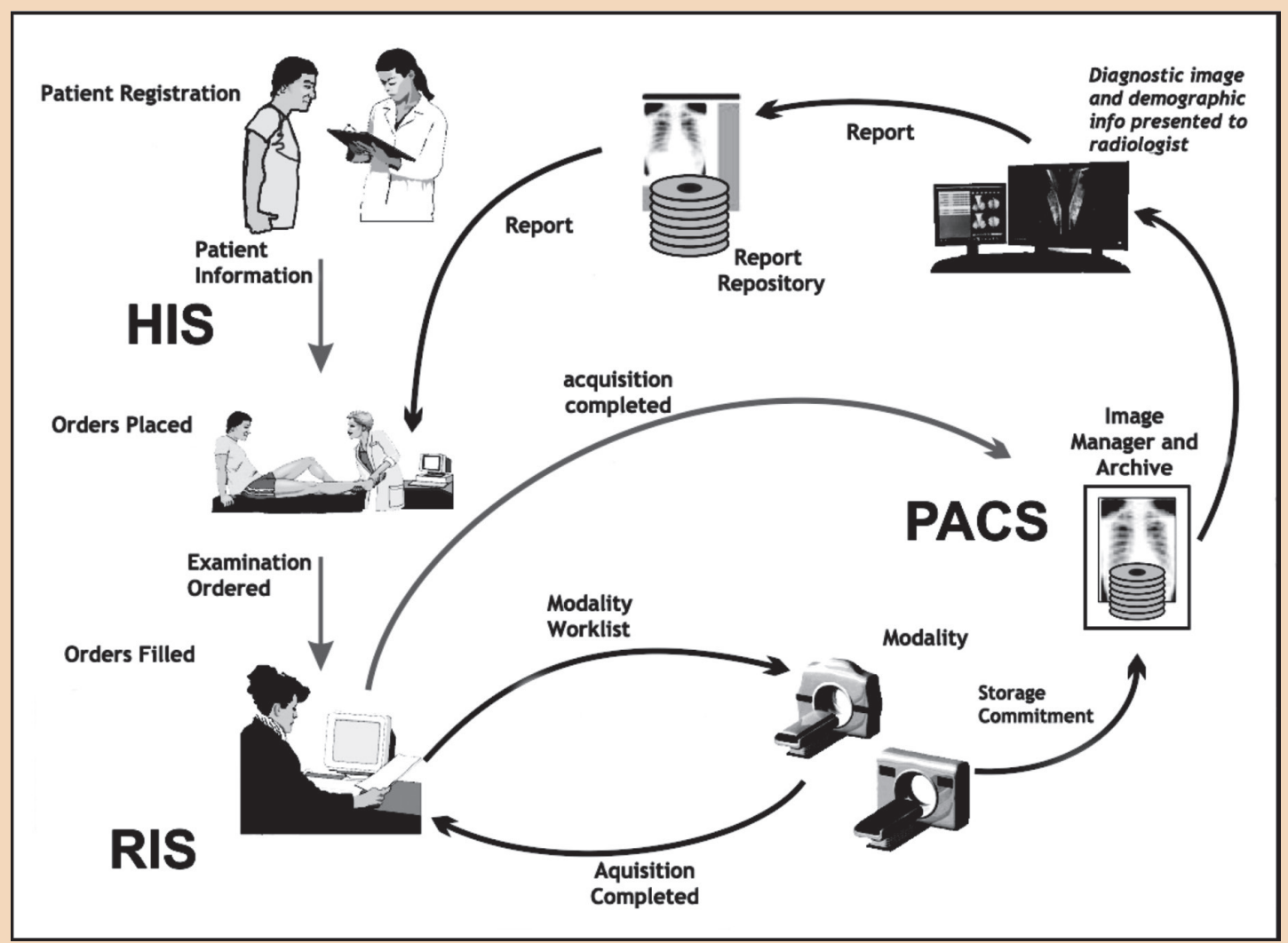

Source: Adapted from Huang (2011).

However, PACS has to be integrated with several healthcare information systems to be clinically effective, including the radiology information system (RIS), the hospital information system (HIS) and other medical information systems (see Fig. 2). It has become an important component of services 
offered by many radiology departments and hospitals around the world. Being integrated to the HIS, all the images and information generated by PACS complies with the three basic principles of information security: confidentiality, integrity and availability.

\section{Figure 2. Generic PACS workflow.}

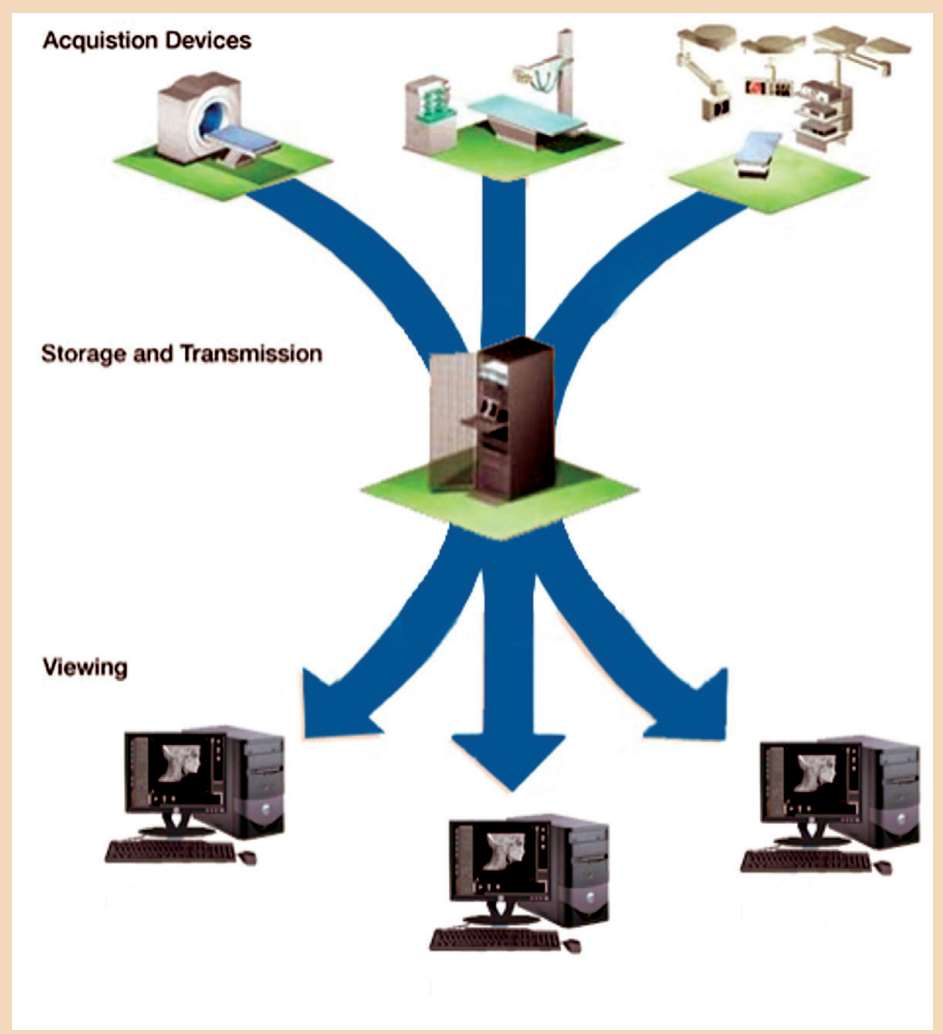

Source: Adapted from Huang (2011).

Such a system is an example of structural process innovation where images are presented to the healthcare provider without traditional film, making large physical storage areas for the film unnecessary, while providing more timely access to the images from multiple locations.

During recent years, INCA has invested around U\$ 1,500,000.00 in PACS' implementation to make access to patients' medical information faster, easier and more secure anywhere from all hospital units. The system was made operational in less than one year, with little impact on the hospital's routine. The large amount of investment in deployment planning and training of medical and IT staff, combined with the sponsorship of the Board of directors, contributed greatly to the success of PACS' implementation.

Before PACS' implementation, each imaging modality, such as X-ray, computed tomography (CT) and magnetic resonance imaging $(\mathrm{MRI})$, had its own printer for printing images. The operation was totally paper and film based. A patient's diagnostic image was always performed using film with light boards on the walls. Film was stored in warehouses occupying large areas. The intense flow of film and paper into hospital units required by this process was leading to losses and do-overs. People in charge of implementation were initially worried about change resistance by the technical staff and interface incompatibilities not supported by the DICOM protocol. Therefore, the rollout strategy was to start the new procedure in the radiology unit and gradually to implement it in other departments. Technicians, physicians and IT people were submitted to a 3-month training program at INCA. The fact that management people at INCA are used to attending in-company courses with external instructors has also contributed much to diminish cultural barriers to innovations. Regarding the cooperation between INCA and Carestream Health (supplier), we can highlight the following points: shared education and training; supplier reputation; agreement on common performance measures; sharing of information, technology, facilities and equipment; participation in the supplier's staff project; and collocation of customers and supplier employees. Being the first Brazilian public hospital in the area of oncology to implement PACS, the aspects of the above-mentioned cooperation were crucial. In the end, resistance was low, 
which challenges the theoretical assumption that resistance to change is a "fact of life" and is bound to happen during any organizational intervention. In addition, it is important to note that obsolescence of old equipment and systems did not occur because of PACS' implementation.

Eliminating the need for film provided a savings of U\$ 650,000.00/year in film, chemicals, water and maintenance. All these savings resulted in 2.5 years for the investment to pay for itself. The new procedure also provided a savings of 8 million liters of water, approximately 15 thousand liters of chemicals for development, and $52 \mathrm{~kg}$ of silver, which has contributed enormously to reducing the environmental impact of the hospital's operation. The numbers of PACS' exams are presented in Table 4.

\section{Table 4: Number of PACS' exams/year}

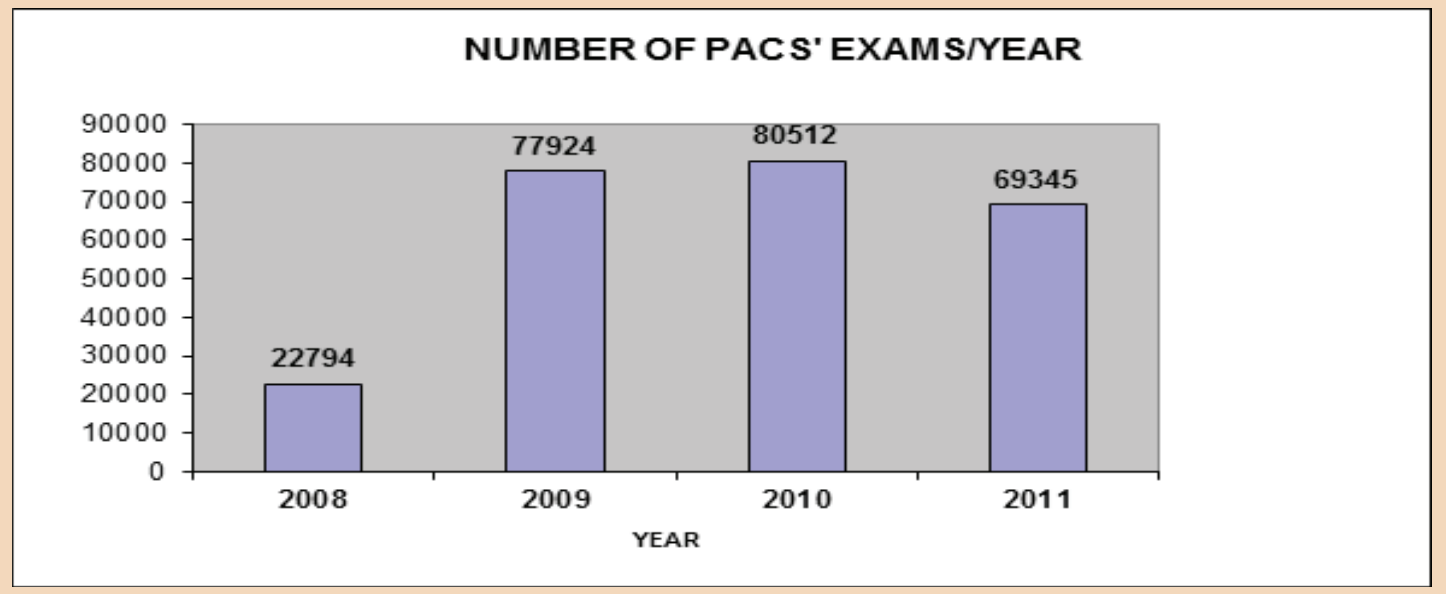

Source: Research data (25 oct 2011).

This study has pursued a better comprehension of the challenges confronted in implementing PACS within INCA hospital units and the strategies applied to ensure its success.

The reduction in INCA's expenditures related to the elimination of film and to higher productivity was sufficient to pay for a good portion of the system's implementation costs. Among the more important benefits, we can point to rapider diagnostic readings, a significant reduction in the number of lost images, a greater number of patients examined, fewer rejected images (and rescheduled exams), accelerated improvements in the productivity of radiologists and technologists, the elimination of film and the chemical products needed to develop it, and improved patient care.

Focusing on innovation and providing high quality care, INCA continues to concentrate on the importance of strategic IT investments as a means to delivering improved patient care. PACS' solution to storage technology has allowed for exceptional speed, scalability and reliability in storing all of INCA patients' medical images. Such results have turned the PACS technology into a key technology for INCA's strategic objectives. On the other hand, one has to agree that the implementation of PACS may have brought some cost switching for INCA. In case the PACS system is abandoned for another, the costs will appear in the form of the need to acquire new licenses, the need to learn a new system and the need to convert programs and data.

\subsection{Main results}

The results of this research demonstrate the relevancy of considering PACS' deployment as a question of organizational change, and not simply as the deployment of technology.

The study investigated a better meaning of the challenges faced in PACS' implementation and of the strategies required to ensure its accomplishment. The relevant factors for its rapid adoption were summarized as follows:

- The decision to adopt PACS does not guarantee success; effective PACS implementation is also necessary;

- Any PACS deployment should be treated not simply as a rollout of new technology but as a project 
that will transform the organization, therefore good communication is crucial;

- Any difficulties may come from misunderstanding the needs of new services, techniques, and technology; i.e., the rollout strategy should involve systematic staff training in operational procedures;

- A strategy that takes into consideration all the technical, economic, organizational and human factors should be adopted, i.e., systemic approach is required;

- Training and education are key factors for inducing organizational innovation;

- Collaboration between partners and good team communication are major drivers of innovation in healthcare.

\section{CONCLUSIONS}

The purpose of this article was to investigate the factors that determined the rapid adoption of PACS at INCA. It is essential to adopt a proactive implementation strategy that takes into consideration all the technical, economic, organizational, and human factors.

If a new technology or technique like PACS is being considered, health systems should consider the principles of quality improvement as they are introduced rather than wait for the inevitable problems to occur. It is essential to recognize the risks and costs of innovation - including the disruptive effects of beneficial innovation - and to improve the training of health professionals to deal with the positive and negative challenges of innovation. It is believed that the high complexity of the PACS technology would have negatively impacted the adoption decision were it not for the very good reputation of the supplier. Improvement definitely depends on change, but change always generates new challenges. Cooperative approaches may be the best way of accomplishing sustainable, positive innovation. The most effective ways to ensure the implementation of new technology like PACS is by working collaboratively.

This investigation has made it clear that process innovation requires leadership and teamwork. Collaboration is one of the major drivers of process innovation in healthcare. Open communication, interpersonal relations and networks, and close connections between innovators are frequently promoted as necessary criteria for an innovative organization. This practice should be encouraged across functional and organizational boundaries.

\section{REFERENCES}

ARAUJO, L. C. G.; GARCIA, A. A.; MARTINES, S. Gestão de Processos. São Paulo: Atlas, 2011.

BAPTISTA, M. O Enfoque Neo-Schumpeteriano da Firma. Encontro Nacional da ANPEC. Disponível em: <http://www.econ.fea.usp.br/vermulm/eae510/o_enfoque_neo_schumpeteriano_da_firma.doc>.

BAUMANN, R. A.; GELL, G. The Reality of Picture Archiving and Communication Systems. Journal of Digital Imaging, v. 13, p.157-169, 2000.

BROWN, J. S. A cultura do risco. HSM Management, v. 49, p. 60-65, 2005.

DAMANPOUR, F.; WALKER, R. M.; AVELLANEDA, C. N. Combinative effects of innovation types and organizational performance: a longitudinal study of service organizations. Journal of Management Studies, v. 46, n. 4, p. 650-675, 2009.

DANIELS, N. Toward ethical review of health system transformations American Journal of Public Health, v. 96, p. 447-451, 2006.

DIXON-WOODS, M.; AMALBERTI, R.; GOODMAN, S. Problems and promises of innovation: why healthcare needs to rethink its love/hate relationship with the new. Quality Safety, v. 20, Supl 1, p. i47-i51, 2011.

EKEDAHL, M.; WENGSTROM, Y. Coping processes in a multidisciplinary healthcare team - a comparison of nurses in cancer care and hospital chaplains. European Journal of Cancer Care, v. 17, p. 42-8, 2008.

FICHMAN, R. G. The diffusion and assimilation of information technology innovations. In: ZMUD, R. B. Framing the Domains of IT Management: projecting the future through the past. Cincinnati: Pinnaflex Educational Resources, 2000. p. 105-127.

GIANESI, I. G. N.; CORREA, H. L. Administração Estratégica de Serviços: operações para a satisfação 
dos clientes. São Paulo: Atlas, 1994.

GONÇALVES, J. E. L. As empresas são grandes coleções de processos. Revista de Administração de Empresas, v. 40, n. 1, p. 6-19, 2000.

PARÉ G.; TRUDEL M. C. Knowledge barriers to PACS adoption and implementation in hospitals. International Journal Of Medical Informatics, v. 76, p. 22-33, 2007.

HARTMAN, M.; MARTIN, A.; MCDONNELL, P.; CATLIN, A. National health spending in 2007: slower drug spending contributes to lowest rate of overall growth since 1998. Health Affairs, v. 28, n. 1, p. 246$261,2009$.

HARTLEY, J. Innovation in governance and public services: Past and present. Public Money and Management, v. 25, n. 1, 27-24, 2005.

HERNANDEZ, J. M. C.; CALDAS, M. P. Resistência à mudança: uma revisão crítica. Revista de Administração de Empresas, v. 41, n. 2, p. $31-45,2001$.

HUANG, H. K. Short history of PACS. Part I: USA, European Journal of Radiology, v. 78, n. 2, p.163, 2011.

IBGE. Pesquisa Industrial Inovação Tecnológica (PINTEC). Rio de Janeiro, 2008. Disponível em: <www. ibge.gov.br>.

JOHANNESSEN, J.; OLSEN, B.; LUMPKIN, G. T. Innovation as newness: what is new, how new, and new to whom. European Journal of Innovation Management, v. 4, n. 1, p. 20-31, 2001.

LESTER H.; HOBBS F. D. R. Major policy changes for primary care: potential lessons for the US New Model of family medicine from the quality and outcomes framework in the United Kingdom. Family Medicine, v. 39, n. 2, p. 96-102, 2007.

LIAW S. S. Understanding user perceptions of world-wide web environments. Journal of Computed Assisted Learning, v. 18, n. 2, p. 137-148, 2002.

MEYERS, P.; SIVAKUMAR, K. Implementation of industrial process innovations: factors, effects, and marketing implications. Journal of Product Innovation Management, v. 16, n. 3, p. 295-311, 1999.

MINTZBERG, H.; AHLSTRAND, B.; LAMPEL, J. Strategy Safari: a guided tour through the wilds of strategic management. New York: Free Press, 2005.

MULGAN, G.; ALBURY, D. Innovation in the public sector. Strategy Unit Cabinet Office. Disponível em: <http://www.cabinetoffice.gov.uk/media/cabinetoffice/strategy/assets/pubinov2.pdf>.

POPE, C. Resisting evidence: the study of evidence-based medicine as a contemporary social movement. Health, v. 7, n. 3, p. 267-282, 2003.

PORTER, M. Estratégia competitiva: técnicas para análise de indústrias e de concorrentes. Rio de Janeiro: Campus, 2005.

RAGATZ, G. L.; HANDFIELD, R. B.; SCANNELL, T. V. Success Factors for Integrating Suppliers into New Product Development . Journal of Product Innovation Management, v. 14, n. 3, p. 190-202, 1997.

SÊMOLA, M. Gestão da Segurança da Informação: uma visão Executiva. Rio de Janeiro: Campus, 2003.

THAKUR, R.; HSU, S. H. Y.; FONTENOT, G. Innovation in healthcare: Issues and future trends. Journal of Business Research, doi:10.1016/j.jbusres.2011.02.022

TIDD, J.; BESSANT, J. Managing Innovation: integrating technological market and organizational change. 4 ed. Chichester: John Willey \& Sons, 2009.

TIGRE, P. B. Gestão da Inovação: a economia da tecnologia no Brasil. Rio de Janeiro: Campus, 2006.

VARKEY, P.; HORNE, A.; BENNET, K. E. Innovation in Health Care: a primer. American Journal of Medical Quality, v. 23, p. 382-388, 2008.

YIN, R. K. Case Study Research: design and methods, 2 ed. London: Sage, 1994. 